\title{
Membrane Vesicles Containing Matrix Metalloproteinase-9 and Fibroblast Growth Factor-2 Are Released Into the Extracellular Space From Mouse Mesoangioblast Stem Cells
}

\author{
MARIA ELENA CANDELA, 'FABIANA GERACI,' GIUSEPPINA TURTURICI,' SIMONA TAVERNA, ${ }^{2}$ \\ IDA ALBANESE,' AND GABRIELLA SCONZO ${ }^{1 *}$ \\ 'Department of Cellular and Developmental Biology, University of Palermo, Palermo, Italy \\ ${ }^{2}$ Department of Biopathology and Biochemical Methods, University of Palermo, Palermo, Italy
}

Certain proteins, including fibroblast growth factor-2 (FGF-2) and matrix metalloproteinase-9 (MMP-9), have proved very effective in increasing the efficacy of mesoangioblast stem cell therapy in repairing damaged tissue. We provide the first evidence that mouse mesoangioblast stem cells release FGF-2 and MMP-9 in their active form through the production of membrane vesicles. These vesicles are produced and turned over continuously, but are stable for some time in the extracellular milieu. Mesoangioblasts shed membrane vesicles even under oxygen tensions that are lower than those typically used for cell culture and more like those of mouse tissues. These findings suggest that mesoangioblasts may themselves secrete paracrine signals and factors that make damaged tissues more amenable to cell therapy through the release of membrane vesicles.

J. Cell. Physiol. 224: I44-I5I, 20I0. (c) 2010 Wiley-Liss, Inc.

Several studies have highlighted the importance of intercellular communication mechanisms involving the release of different types of vesicles into the extracellular space by cultured cells or organized tissues (Hugel et al., 2005; Cocucci et al., 2009). Some types of vesicles, which are distinct from the exosomes released upon exocytosis of multivesicular bodies, bud directly from the plasma membrane (Cocucci et al., 2009). These spherical structures have proteins and lipids similar to those present in the plasma membrane of the cells from which they originate and their content differs depending on the cell type, indicating the specificity of the process (Beaudoin and Grondin, 1991).

Reports have shown that vesicles independent of their origin can transfer biological information between cells, acting as vectors of signaling molecules (Martínez et al., 2005). Vesicle release from cells has been described under both physiological (Beaudoin and Grondin, 1991; Taraboletti et al., 2002) and physiopathological conditions (Freyssinet, 2003), and may also take place in tumor cells (Taverna et al., 2003; Millimaggi et al., 2006; Taraboletti et al., 2006). The mechanisms governing vesicle production and release are far from being clearly understood. However, it is known that cholesterol-rich microdomains of the plasma membrane are involved in vesicle production (Pilzer et al., 2005), and supplementation of culture medium with serum as well $\mathrm{Ca}^{2+}$ ions may be required to stimulate vesicle shedding in vitro (Taraboletti et al., 2002; Taverna et al., 2003; Pilzer et al., 2005; Ratajczak et al., 2006a). Released vesicles may remain near the cells of origin, but are also found in the blood and other biological fluids, indicating that they can transport their cargo in an environmentally protected form and act at a distance (Martínez et al., 2005). Vesicle cargo may be delivered to other cells, and recent reports have demonstrated microRNA transfer from embryonic stem cell to mouse embryonic fibroblasts via microvesicles, indicating a regulated transfer process (Yuan et al., 2009). Embryonic stem cells are also capable of shedding microvesicles containing
mRNAs and ligands (Ratajczak et al., 2006b), indicating that this process can be a mechanism for paracrine signaling. Against this backdrop, we explored the possibility that mouse

mesoangioblast stem cells release vesicles containing signaling molecules that may have relevant biological functions. Mouse mesoangioblasts are vessel-associated multipotent stem cells that are capable of differentiating into different mesodermal cell types (Minasi et al., 2002). An important property of mesoangioblasts is their ability to cross the endothelial barrier; when injected into the mouse circulation for repair therapy, they localize to experimentally damaged tissues, attracted by high mobility group box-I protein (HMGB-I) released from necrotic cells (Palumbo et al., 2004; Galvez et al., 2006). Indeed, the capacity of intra-arterially delivered mesoangioblast to reduce the severity of muscular dystrophy in mice and dogs, and ameliorate myocardial damage in infarcted mouse hearts has been demonstrated (Sampaolesi et al., 2003, 2006; Galli et al.,

Maria Elena Candela and Fabiana Geraci contributed equally to this work.

Contract grant sponsor: University of Palermo;

Contract grant number: ORPA06K25X.

Contract grant sponsor: Banco di Sicilia Foundation;

Contract grant number: PR96.6/07.

Contract grant sponsor: FSE-PON;

Contract grant number: III.4/2006.

*Correspondence to: Gabriella Sconzo, Dipartimento di Biologia Cellulare e dello Sviluppo, edificio 16 Viale delle Scienze, Università di Palermo, 90128 Palermo, Italy. E-mail: gasc@unipa.it

Received 16 September 2009; Accepted 20 January 2010

Published online in Wiley InterScience (www.interscience.wiley.com.), 15 March 2010. DOI: $10.1002 / j c p .22111$ 
2005). Gene expression analyses have shown that mesoangioblasts express molecules such as fibroblast growth factor-2 (FGF-2), HGF, and IGF-I that confer on themselves properties important in repairing damaged tissues. In the current study, we found that mouse mesoangioblasts produce and release plasma membrane vesicles that contain proteins such as FGF-2 and matrix metalloproteinase (MMP-9) that have proved important in cell therapy. Because these molecules are encapsulated, they are initially protected from the environment when released into the extracellular space.

\section{Materials and Methods}

Cell culture and treatment

Mouse A6 stem cells were grown on collagen I-coated plates in Dulbecco's modified Eagle medium (DMEM; Invitrogen, Carlsbad, CA) with or without $10 \%$ fetal bovine serum (as indicated in the text) in a humidified $5 \% \mathrm{CO}_{2}$ atmosphere at $37^{\circ} \mathrm{C}$. For experiments with lower oxygen tension, cells were grown as previously described (Wright and Shay, 2006). For pharmacological experiments, cells were treated with nocodazole, a drug for microtubule depolymerization, (Sigma-Aldrich, St. Louis, MO) for I8 $(2.5 \mu \mathrm{M})$ or $3 \mathrm{~h}(3 \mu \mathrm{M})$; cytochalasin $\mathrm{B}$, a drug which impairs actin microfilaments polymerization and elongation by capping filament plus ends (Sigma) for I $8(2 \mu \mathrm{M})$ or $3 \mathrm{~h}(4 \mu \mathrm{M})$; and methyl$\beta$ cyclodextrin (Sigma) for $6 \mathrm{~h}$ ( $2.5 \mathrm{mM})$. HT- 1080 cells were grown in RPMI (Invitrogen) medium supplemented with 10\% fetal bovine serum in a humidified $5 \% \mathrm{CO}_{2}$ atmosphere at $37^{\circ} \mathrm{C}$.

\section{Three-dimensional collagen gel matrix culture}

Cells were resuspended in culture medium containing $0.65 \mathrm{M}$ $\mathrm{NaHCO}_{3}$. One volume of acid-soluble type-I collagen solution was mixed with one volume of $A 6$ cell suspension. A $100-\mu$ l aliquot of this solution was plated onto $3-\mathrm{mm}$ diameter dishes and immediately warmed to $37^{\circ} \mathrm{C}$ to form a gel. After polymerization, each gel was overlaid with $200 \mu$ l of medium.

\section{Phalloidin staining of collagen gels}

Collagen gels were fixed in $1.85 \%$ formaldehyde for $5 \mathrm{~min}$ at room temperature and then washed three times with PBS $(68 \mathrm{mM} \mathrm{NaCl}$, I. $3 \mathrm{mM} \mathrm{KCl}, 4 \mathrm{mM} \mathrm{Na} \mathrm{HPO}_{4}, 0.4 \mathrm{mM} \mathrm{CaCl}, 0.2 \mathrm{mM} \mathrm{MgCl}$, $\left.0.8 \mathrm{mM} \mathrm{KH}_{2} \mathrm{PO}_{4}\right)$ for 5 min each. Gels were incubated with fluorescein-conjugated phalloidin in I $\times$ PBS ( $\mathrm{I}: 200$ dilution) for $\mathrm{I} \mathrm{h}$ at $37^{\circ} \mathrm{C}$. Collagen gels were coverslip-mounted with DABCO (diazabicyclo 2, 2, 2 octane; Sigma ${ }^{\mathbb{R}}$ ). Fluorescent cells were analyzed using an Olympus BX50 microscope equipped with a Nikon sight DS-UI.

\section{Purification of vesicles from medium}

Vesicles were purified from medium as described (Dolo et al., 1994). Briefly, medium conditioned by subconfluent healthy cells for different lengths of time was centrifuged at $2,000 \mathrm{~g}$ for $10 \mathrm{~min}$ and at $4,000 \mathrm{~g}$ for $15 \mathrm{~min}$. The supernatant was ultracentrifuged at $105,000 \mathrm{~g}$ for $90 \mathrm{~min}$, and pelleted vesicles were resuspended in PBS. Protein content of isolated vesicles was determined using the Bradford microassay method (Sigma) with bovine serum albumin as a standard.

\section{Acetylcholinesterase assay}

Vesicle release was quantified by measuring the activity of acetylcholinesterase (AchE). Briefly, vesicles (5 $\mu \mathrm{l})$ were suspended in PBS $(95 \mu \mathrm{l})$ and incubated with $1.25 \mathrm{mM}$

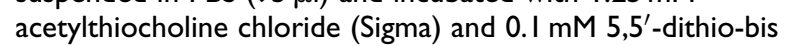
(2-nitrobenzoic acid) $\left(3,3^{\prime}-6\right.$; Sigma). PBS was then added to a final volume of I ml, and the change in absorbance at $412 \mathrm{~nm}$ was monitored every $5 \mathrm{~min}$ for $20 \mathrm{~min}$.

\section{Trypan blue dye exclusion}

Cell viability was measured by staining cells with trypan blue dye and then counting, as described elsewhere (McCloskey et al., 1998).

\section{Preparation of protein extracts}

Protein extracts were prepared as previously described (Geraci et al., 2006). Protein concentration in extracts was determined using the Bradford microassay method (Sigma) with bovine serum albumin as a standard.

\section{Coomassie staining}

Whole-cell extract and vesicle proteins were separated by SDSPAGE on 10\% gels. Gels were stained with Coomassie Blue as described previously (Barnouin, 2004).

\section{Western blots}

Whole-cell extract and vesicle proteins were separated by SDSPAGE on $10 \%$ gels and transferred to an ECL-Hybond membrane (Amersham Biosciences, Piscataway, $\mathrm{NJ}$ ) using a mini-electroblot apparatus (Biorad, Hercules, CA). After blocking for $2 \mathrm{~h}$ in TBST buffer (I $0 \mathrm{mM}$ Tris- $\mathrm{HCl}, \mathrm{pH} 7.5,150 \mathrm{mM} \mathrm{NaCl}, 0.2 \%$ Tween-20) containing $5 \%$ non-fat dry milk, membranes were incubated overnight with the following antibodies: mouse polyclonal anti-actin ( $1: 800$ dilution; Neomarkers, Fremont, CA), mouse monoclonal anti- $\beta$-tubulin ( I:400 dilution; Sigma), rabbit polyclonal anti-filamin ( I:200 dilution; Santa Cruz, Santa Cruz, CA), mouse monoclonal anti-VE cadherin (I:200 dilution; R\&D Systems, Minneapolis, MN), rabbit polyclonal anti caveolin-I (I:200 dilution; Sigma), rabbit polyclonal anti-sphingosine kinase-I (SphK-I, I:I00 dilution; Abgent, Inc., San Diego, CA). Alkaline phosphatase-conjugated anti-rabbit and anti-mouse ( $1: 5,000$ dilution; Promega Inc., Madison, WI) antibodies were used as secondary antibodies. Horseradish peroxidase-conjugated antirabbit ( $1: 5,000$ dilution; Promega) antibody was used as secondary antibodies for filamine.

\section{GM-I ganglioside dot-blot assays}

A6 cells and vesicles were incubated with HRP-conjugated cholera toxin subunit B (dilution I: 500; Sigma) in PBS for I h at $0^{\circ} \mathrm{C}$. After washing twice with PBS, cells were lysed with $1 \%$ Triton $X-100$ for $30 \mathrm{~min}$ at $0^{\circ} \mathrm{C}$, whereas vesicles were resuspended in PBS. Cell lysates and vesicles $(30 \mu \mathrm{g})$ were transferred to ECL-Hybond (Amersham () membranes. The membranes were then dried, washed with PBS and developed using enhanced chemiluminescence.

\section{Gelatin zymography}

Samples were electrophoresed on 7.5\% SDS-PAGE containing $6 \mathrm{mg} / \mathrm{ml}$ gelatin type B (Sigma). Vesicles samples were diluted in SDS-PAGE sample buffer under non-reducing conditions without heating. After electrophoresis, gels were washed in $2.5 \%$ Triton $X-100$, incubated overnight at $37^{\circ} \mathrm{C}$ in buffer containing $50 \mathrm{mM}$ Tris- $\mathrm{HCl}, \mathrm{pH} 7.5,2 \mathrm{mM} \mathrm{CaCl}_{2}$ and I.5\% Triton X-100, or in buffer containing $50 \mathrm{mM}$ Tris- $\mathrm{HCl}, \mathrm{pH} 7.5,2 \mathrm{mM}$ EDTA and I.5\% Triton $\mathrm{X}-100$, and then stained with Comassie Blue R 250 (Sigma) for $48 \mathrm{~h}$. Vesicles samples from HT- 1080 cells were used as a reference standard for pro-MMP-9, pro-MMP-2, MMP-9, and MMP-2 (Ginestra et al., 1997). Gelatinase activity was visualized as a clear zone against a blue background, indicating proteolysis of substrate.

\section{Vesicle immunofluorescence}

Isolated vesicles were fixed with $3.7 \%$ paraformaldehyde for $40 \mathrm{~min}$ in culture medium and then centrifuged at $2,700 \mathrm{~g}$ for $5 \mathrm{~min}$. Pelleted vesicles were washed sequentially with $\mathrm{PBS}$ and $\mathrm{PBS}$ containing $0.1 \mathrm{M}$ glycine, and then cytocentrifuged onto poly L-lysine-coated slides at I,000 $\mathrm{g}$ for $5 \mathrm{~min}$. Slide-mounted vesicles were 
permeabilized with $0.05 \%$ Triton $X-100$ and washed three times with PBS (5 min each), and then incubated with mouse monoclonal anti-FGF2 antibody solution ( I:50 dilution; Upstate Lake Placid, $\mathrm{NY}$ ) overnight at $4^{\circ} \mathrm{C}$ or with FITC-conjugated cholera toxin subunit B (I0 $\mathrm{gg} / \mathrm{ml}$; Sigma) for I h. After washing, slides were incubated with FITC-conjugated anti-mouse secondary antibodies ( I:400 dilution; Amersham) After a final wash, slides were coverslip-mounted with DABCO. Fluorescent vesicles were analyzed using an Olympus BX50 microscope equipped with a Nikon sight DS-UI.

Assay for urokinase plasminogen activity (UPA) activity

GM7373 cells $\left(1.75 \times 10^{6}\right)$, plated at a density of $7 \times 10^{4}$ cells $/ \mathrm{cm}^{2}$, were grown for $28 \mathrm{~h}$ in a serum-free medium. After that cells were incubated for 18-24h with A6-vesicle. After removing the culture supernatant, the cells were washed twice with PBS, scraped with a rubber policeman, and then collected by centrifugation at $800 \mathrm{~g}$ for $10 \mathrm{~min}$ at $4^{\circ} \mathrm{C}$. Cells were lysed, protein concentration was measured by the Bradford method, and cell extracts $(30 \mu \mathrm{g}$ proteins) were separated by electrophoresis on 7.5\% SDS-PAGE. Zymography was performed as previously described (Vassalli et al., 1984); overlay gels contained $3 \%$ non-fat dry milk and $40 \mu \mathrm{g} / \mathrm{ml}$ bovine plasminogen (Sigma). Densitometric analysis of the lysis bands was performed using Science ID Image Analyzer software (Eastman Kodak Co, Rochester, NY). White bands in images indicative of caseinolysis were converted to dark bands to better display the activity. Neutralizing anti-FGF2 (Upstate

Biotechnology), mouse monoclonal anti- $\beta$-tubulin (Sigma) and mouse monoclonal anti-Hsp70/Hsc70 (Sigma) antibodies were used in this assay.

\section{Flow cytometry}

Isolated vesicles were diluted in I ml of filtered PBS containing flow cytometer calibration polystyrene microspheres with the following diameters: I.0, 2.0, 4.0, 6.0 $\mu \mathrm{m}$ (Invitrogen) and then analyzed on a BD FACSCanto (Franklin Lakes, NJ) for forward and $90^{\circ}$ side scatter (SS). Forward scatter (FS) and SS parameters were plotted on logarithmic scales to best cover a wide size range.

\section{Results \\ Mesoangioblast vesicle production and vesicle characterization}

To explore the possibility that mouse mesoangioblasts release proteins into the extracellular space through a vesicle shedding process as other cell types do (Cocucci et al., 2009), we cultured the $\mathrm{A} 6$ mesoangioblast clone in three-dimensional collagen gels (Noble, 1987; D'Agostino et al., 2006). Staining with fluorescein conjugated-phalloidin showed the presence of vesicle structures near the plasma membrane of cells (Fig. IA). Mesoangioblasts also produced vesicles under low-oxygen tension; that is, under conditions more similar to those of mammalian tissues (Wright and Shay, 2006; Fig. IB). It has been suggested that the high-oxygen content used routinely in cell culture may be somewhat of a stress on primary cells. However, our observations preclude the possibility that transfer of mesoangioblasts from aortic tissue (low-oxygen tension) to cell culture (higher oxygen tension) induces vesicle production as a result of hyperoxygen stress. In contrast to other cells that shed vesicles only in complete medium (Dolo et al., 1994; Taverna et al., 2003), A6 mesoangioblasts also produced vesicles in serum-free medium (Fig. IC).

Vesicles were studied by recovering them from conditioned medium at different times after medium replacement, as described (Galli et al., 1993; Dolo et al., 1994). The protein content of the vesicle pellet reached a maximal level within the first $3 \mathrm{~h}$, after which the level decreased to a lower value and remained constant (Fig. 2A). The stability of vesicles was assessed by isolating cell-conditioned medium and analyzing vesicle amounts at different times. As shown in

Figure $2 B$, vesicles released by $A 6$ cells are not stable; thus, the constant level observed in the shedding curve (Fig. 2A) corresponds to a steady state that reflects vesicle production and turnover. Vesicle shedding in serum-free medium followed the same trend, but the level of shedding was much lower (Fig. 2A). Flow cytometry assays showed that $A 6$ vesicles vary in size, but are $\leq I \mu \mathrm{m}$ in diameter (Fig. 2C), a size that excludes the possibility that these vesicles are exosomes (Cocucci et al., 2009).

\section{Vesicle shedding requires integrity of the tubulin cytoskeleton and raft microdomains}

We next examined whether disruption of cytoskeletal structures affects $A 6$ mesoangioblast vesicle shedding. A6 cells treated with cytochalasin B showed an altered round shape (not shown), but the treatment did not affect vesicle production (Fig. 3). In contrast, nocodazole treatment reduced vesicle shedding by $30 \%$ (Fig. 3). It has recently been suggested that laterally mobile lipid rafts in the plasma membrane may sort into curved, cholesterol-rich membrane regions (Stein and Luzio, 1991; Del Conde et al., 2005; Hägerstrand et al., 2006). To determine whether disrupting the integrity of these cholesterol-rich microdomains affects A 6 cell vesicle shedding, we investigated vesicle release after methyl- $\beta$-cyclodextrine (MBC) treatment, which inhibits raft organization. As shown in Figure 3, MBC treatment reduced vesicle release to $55 \%$ of control levels, indicating the involvement of these plasma membrane lipid structures in vesicle shedding. Cell viability,
A

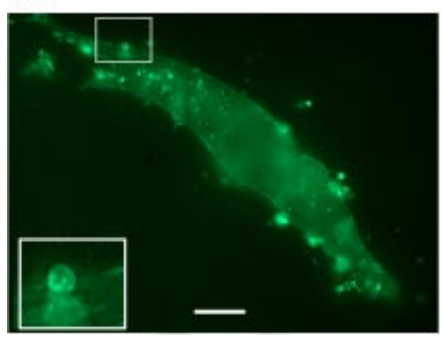

B

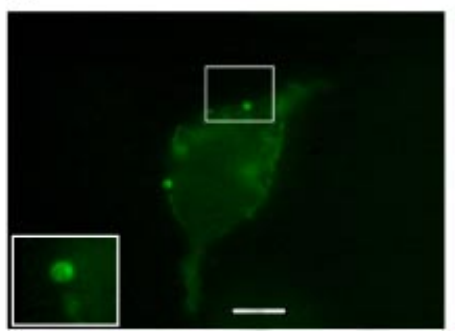

C

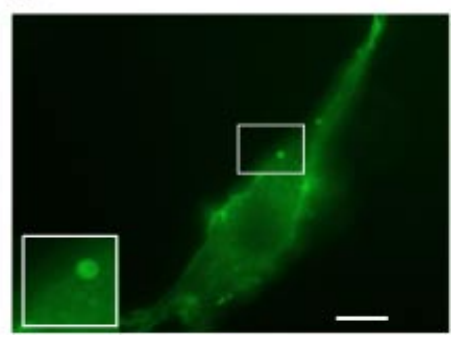

Fig. I. Membrane vesicle shedding by mesoangioblasts. A: Fluorescence observation of FITC-phalloidin labeled mesoangioblasts cultured in three-dimensional collagen gels in the presence of serum. Vesicles are shown near the cell. B: Same as in (A), but in low-oxygen tension (8\%). C: Cells cultured in three-dimensional collagen gels without serum. Insets, a higher magnification of the picture depicted in panels A, B, C (square). Many cells were examined and a representative cell is shown. Scale bars: $10 \mu \mathrm{m}$. 

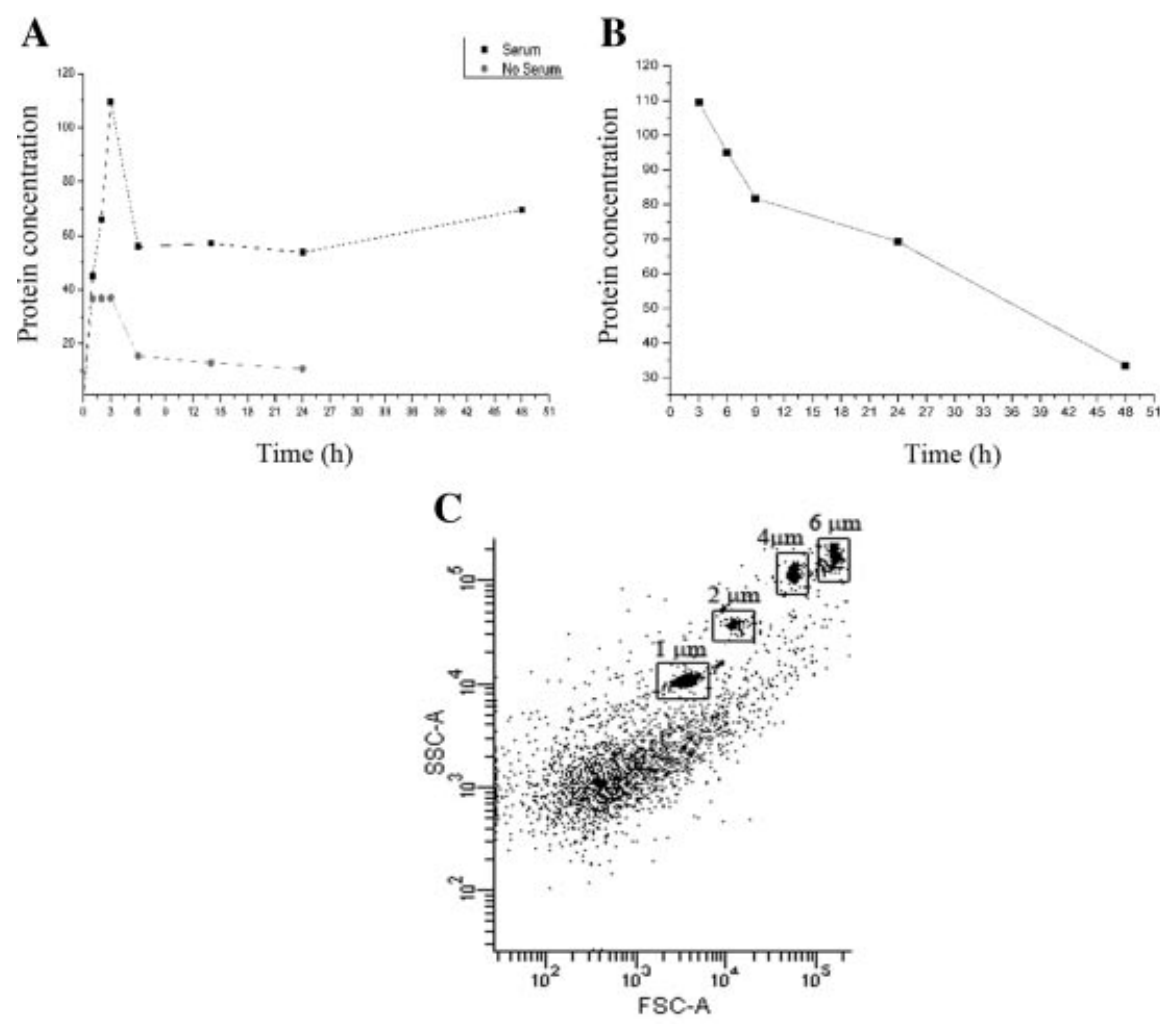

Fig. 2. Time course of vesicle shedding and vesicle stability in mesoangioblast cells. A: Time course of vesicle shedding. Protein content of vesicles recovered from medium conditioned by subconfluent healthy $A 6$ cells at $I, 2,3,6,14,24$, and $48 \mathrm{~h}$. B: Shed-vesicle stability in mesoangioblast cells was determined by measuring the protein content of the vesicle pellets recovered from medium conditioned by A6 cells for $3 \mathrm{~h}$ and incubated at $37^{\circ}$ $\mathrm{C}$ for 6,9,24, and $48 \mathrm{~h}$. C: Flow cytometry analysis of isolated mesoangioblast vesicles. Data from one experiment representative of three. SSC, side scatter; FSC, forward scatter. Squares indicate calibration polystyrene microspheres with the following diameters: I.0, 2.0, 4.0, and 6.0 $\mu \mathrm{m}$.

assessed by trypan-blue staining, was not significantly affected by treatments ( $<3 \%$ dead cells), suggesting that nocodazole and MBC-induced reduction in vesicle shedding was not due to a generalized cytotoxic effect of the drugs.

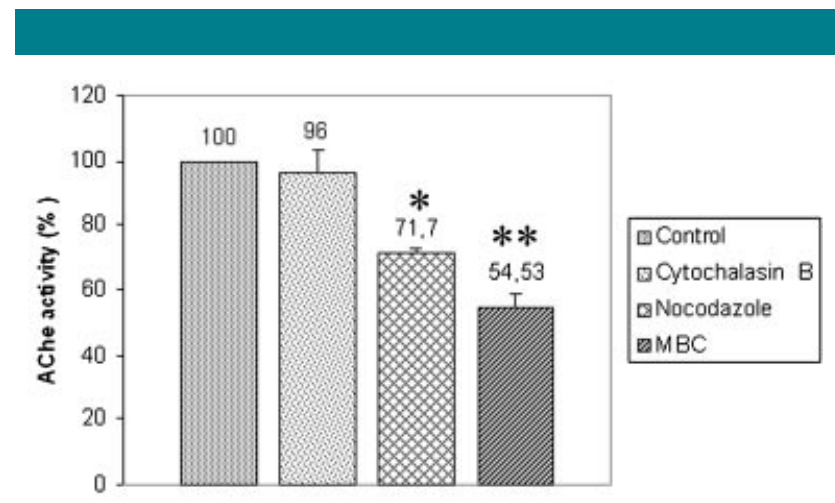

Fig. 3. Effect of cytochalasine B, nocodazole and methyl- $\beta$ cyclodextrin treatment on vesicle shedding. Cells were incubated in the presence of cytochalasine B, nocodazole, and methyl- $\beta$ cyclodextrin as described in the "Materials and Methods." Vesicles were collected from the cultured medium and quantified by measuring AchE activity. Each bar is the mean \pm SEM of three independent experiments. Significance was calculated using Student's $t$-test, and $P$-values versus control of $<0.0010\left(^{*}\right)$ and $<0.0$ I $\left({ }^{* *}\right)$ are indicated.

\section{Protein content of mesoangioblast vesicles}

An electrophoretic analysis of vesicle protein content revealed a complex pattern (Fig. 4A), consistent with previously reported content analyses of vesicles shed from other cell types (Hegmans et al., 2004). A comparison of the whole-cell and vesicle protein patterns showed that the protein composition of the vesicle is different from that of the cell as a whole (Fig. 4A).

As a first step in the characterization of vesicle structure, we investigated whether vesicles contain structural proteins that are part of the cell cortex. Immunoblot analyses of vesicle lysates showed the presence of actin (Fig. 4B), as already highlighted by phalloidine fluorescent images (see Fig. IA). Filamin, a cytoskeletal protein that cross-links actin fibers, was also present as were traces of $\beta$-tubulin (Fig. 4B). Both actin and filamin are important constituents of the cell cortex.

We also explored the presence of proteins characteristic of the plasma membrane. Immunoblots showed that vesicles contained VE-cadherin protein (Fig. 4B), consistent with previous reports that VE-cadherin is expressed at the mRNA level in A6 mesoangioblasts (De Angelis et al., I 999; Minasi et al., 2002). This protein, which is essential for cell-cell adhesion, is also involved in proliferative processes, but its role in mesoangioblasts remains unexplored.

Because MBC-mediated membrane disruption induced a significant decrease in vesicle shedding, we investigated whether lipid rafts are also constituents of vesicles. To this end, we probed for the presence of two raft markers, caveolin-I and 
A

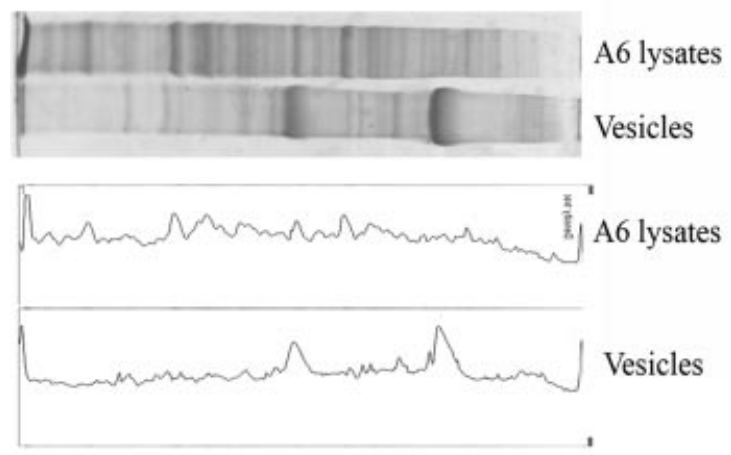

C

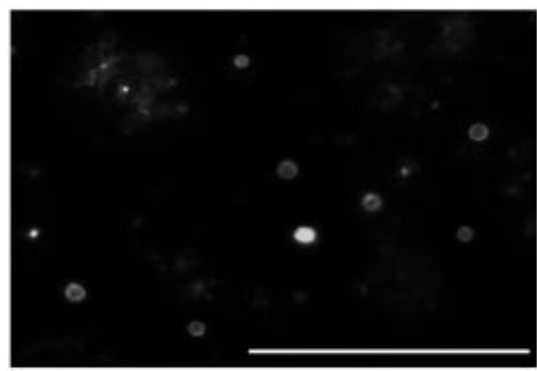

B

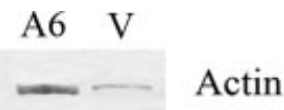

.

Filamine

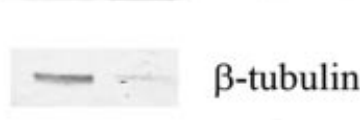

Caveolin 1

VE-Cadherin
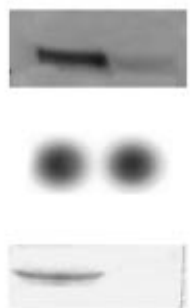

GM1

SphK 1

D



Fig. 4. Comparison of protein's pattern in A6 mesoangioblast cells and in shed vesicles. A: Separation of A6 lysates and A6 cell-derived vesicle proteins on 8\% SDS-PAGE. Upper panel: A6 lysates; Lower Panel: membrane vesicles. Profiles of densitometric analysis are shown. B: Immunoblot assays of protein lysates: A6 cells (left) and membrane vesicles (right). Protein lysates were incubated using antibodies against actin, filamin, tubulin, caveolin-I, VE-cadherin, SphK-I. Dot-blot assay with HRP cholera toxin B subunit for GM-I ganglioside. C: Cytocentrifuged isolated vesicles, staining with FITC-conjugated cholera toxin B subunit. D: Cells cultured in three-dimensional collagen gels, labeled with fluorescent cholera toxin B subunit. Scale bars: $10 \mu \mathrm{m}$.

GM-I ganglioside (Wang and Paller, 2006), by immunoblot and dot-blot, respectively. As shown in Figure 4B, both lipid raft markers were present in isolated vesicles. The presence of GM-I on mesoangioblasts (Fig. 4D) and isolated, cytocentrifuged vesicles (Fig. 4C) was further confirmed by fluorescence staining with the cholera toxin B subunit, which binds GM-I. This finding indicates that raft microdomains are constituents of vesicles and accounts for the ability of

MBC-mediated lipid raft disruption to reduce vesicle shedding. Other molecules known to be produced by mesoangioblasts, such as SphK-I (Donati et al., 2009), were not present in vesicle lysates at levels detectable by the assay used (Fig. 4B) indicating that protein release through vesicles is a regulated process.

\section{Vesicle proteins with extracellular functions}

Injection of tendon fibroblasts engineered to express MMP-9 metalloproteinase into dystrophic mice has recently been shown to reduce collagen deposition (Gargioli et al., 2008; Lolmede et al., 2009), and mesoangioblasts have been reported to be effective in repairing damaged tissues (Sampaolesi et al.,
2003; Galli et al., 2005). To determine whether mesoangioblasts synthesize and secrete active metalloproteinases, we analyzed shed vesicles using zymography. As shown in Figure 5 (lane I), zymography revealed the presence of two metalloproteinases, MMP-9 and MMP-2, in extracts of mesoangioblast vesicles; both were present in their activated form, as shown by bands of 79 and $58 \mathrm{kDa}$, respectively (Fig. 5). HTI080 vesicles were used as a molecular mass standard (Fig. 5 lane 2), as demonstrated (Ginestra et al., 1997). Zymography further indicated that proMMP-2 (63 kDa) and pro-MMP-9 (9I kDa) are also released. In the presence of EDTA, which blocks the metalloproteinase activity, no bands were visible (data not shown). Some previous studies in different cultured cell lines demonstrated cell capacity to release MMP into conditioned medium through vesicle shedding (Chavez-Muñoz et al., 2009), but it is the first time that this mechanism has been observed for stem cells. These findings are important in the context of mesoangioblast therapy, suggesting that the action of these MMPs may lead to a reduction in collagen deposition as observed when engineered fibroblasts are injected in dystrophic mice (Gargioli et al., 2008). 


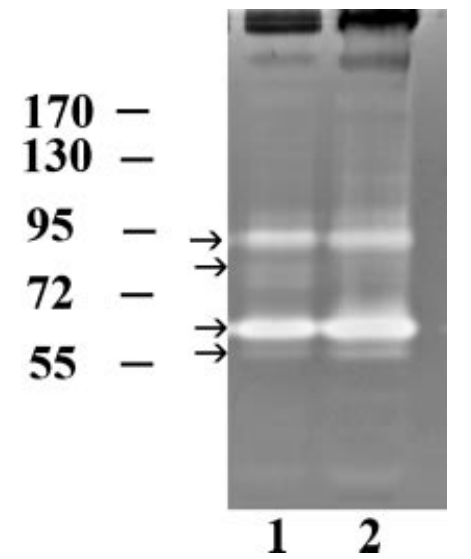

Fig. 5. Gelatine zymography of vesicle-associated gelatinase. Vesicles were purified from cell-conditioned medium containing $10 \%$ FBS and analyzed by gelatine zymography as described in "Materials and Methods." Lane I: vesicle lysates from mesoangioblasts; Lane 2: vesicle lysates from HTI 080 cells. Sizes are indicated in kDa. Arrows indicate the proMMP9 $(9 \mathrm{l} \mathrm{kDa})$ and its activated form $(79 \mathrm{kDa})$, the proMMP2 $(63 \mathrm{kDa})$ and its activated form $(58 \mathrm{kDa})$.

As reported by Galli et al. (2005), mesoangioblasts produce FGF-2. There are two types of FGF-2: one type has a high molecular mass and contains a classical $\mathrm{N}$-terminal nuclear localization signal, and the other is a low molecular mass type. This latter isoform, which lacks a detectable secretion signal sequence is known to be released through a mechanism independent of the endoplasmic reticulum/Golgi pathway. To determine whether FGF-2 is released into the extracellular milieu through membrane vesicles, as is the case in other cell types (Taverna et al., 2008), we analyzed isolated vesicles using immunofluorescence. As shown in Figure 6, purified and cytocentrifuged vesicles do contain FGF-2, indicating that FGF-2 is indeed exported outside the cell through shed vesicles. To assess the biological significance of vesicle-associated FGF-2, we sought to verify whether mesoangioblast vesicles were capable of delivering FGF-2 to endothelial cells and activate downstream signaling. To accomplish this, we incubated GM7373 endothelial cells with vesicles purified from mesoangioblast-conditioned medium and assayed them for uPA production, a characteristic response to FGF-2 signaling.

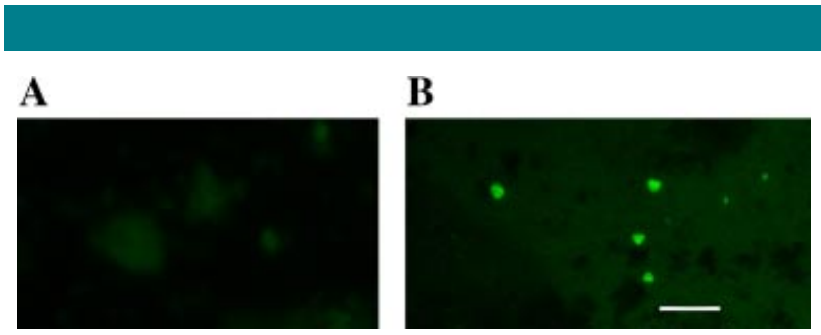

Fig. 6. A6 shed vesicles contain FGF-2. A: Negative control, of isolated and cytocentrifuged vesicles without anti-FGF2 antibodies. B: Immunofluorescence of isolated and cytocentrifuged vesicles using anti-FGF-2 antibody. Scale bar: $10 \mu \mathrm{m}$. A: Immunofluorescence of isolated and cytocentrifuged vesicles incubated only with the secondary antibody as negative control. B: Immunofluorescence of isolated and cytocentrifuged vesicles using anti-FGF-2 antibody. Scale bar: $10 \mu \mathrm{m}$. [Color figure can be viewed in the online issue, which is available at www.interscience.wiley.com.]
Casein/plasminogen zymography of GM7373 cell extracts showed that GM7373 cell-associated uPA activity was increased by mesoangioblast vesicles in a dose-dependent manner (Fig. 7A). To confirm that this effect was due to FGF-2 associated with vesicles and not to other vesicle contents, we incubated GM7373 cells with both vesicles and a neutralizing anti-FGF2 antibody. These assays showed that the anti-FGF-2 antibody blocked uPA production, indicating that the response is, in fact, attributable to FGF-2 and not to some other molecules contained within vesicles (Fig. 7B). In fact, nonspecific antibodies (anti-Hsp70/Hsc70 or anti- $\beta$ tubulin) had no effect on uPA activation.

This is the first demonstration that FGF-2 produced by mesoangioblasts is exported into the extracellular milieu by vesicles and serves as an active signal molecule capable of activating uPA production in endothelial cells.

\section{Discussion}

In the present study, we showed that FGF-2 and the metalloproteinases, MMP-9 and MMP-2 - all factors important for mesoangioblast biological function-are enclosed within vesicular structures and released in an active form into the extracellular space. A comparison of vesicle release and stability curves revealed a process of continuous vesicle production and turnover. The stability curve also indicated that vesicles are stable in the culture medium for several hours, and therefore their contents could be preserved in the extracellular space for some period of time. This is supported by the presence in the vesicles plasma membrane of lipid rafts, which may confer some stiffness to these structures. The integrity of lipid rafts is required for vesicle production, as shown by the fact that A6 cell treatment with MBC, which disrupts rafts, decreases the production of vesicles. The presence of the cytoskeletal proteins, actin, and filamin, may reinforce the vesicles' round shape. Importantly, the presence of GM-I ganglioside and $V E$-cadherin in $A 6$ vesicles implies that the vesicles may be generated from the plasma membrane. Mesoangioblast vesicle production occurred even in the absence of serum, albeit at very low levels relative to that observed in fully supplemented medium. In contrast, the presence of serum in the culture medium is absolutely required for vesicle production in other cell types, such as endothelial cells and cancer cells (Taraboletti et al., 2002; Taverna et al., 2003; Millimaggi et al., 2006).

Mesoangioblasts are a population of stem cells characterized by the ability to migrate in vivo to sources of inflammation in response to HMGB-I released into the extracellular milieu from necrotic cells (Palumbo et al., 2004; Galvez et al., 2006). These cells have been shown to reduce the severity of muscular dystrophy when delivered intra-arterially in dystrophic mice or dogs (Sampaolesi et al., 2003, 2006), and to ameliorate myocardial damage in infarcted mouse hearts (Galli et al., 2005). An analysis of gene expression has revealed that mesoangioblasts express growth factors, including FGF-2, that prevent cardiomyocyte apoptosis and stimulate proliferation of smooth muscle cells in newly formed vessels (Galli et al., 2005). However, the mechanism governing secretion of FGF-2, which lacks a detectable secretion signal sequence, has remained poorly understood. Our current findings shed light on this mechanism, demonstrating that, in culture, mesoangioblasts release vesicles containing FGF-2 into the extracellular space. That this FGF-2 is present in an active form is demonstrated by its ability to induce synthesis of uPA in endothelial cells. It is interesting that this growth factor is released from these stem cells in a relatively protected structure.

Notably, the vesicles produced by $A 6$ cells also contained the activated form of MMP-2 and MMP-9. Cossu and colleagues have shown that MMP-9, when expressed by modified tendon fibroblasts, restores vascular networks and reduces the 
A

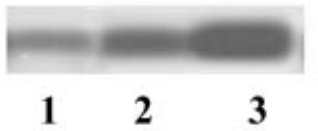

B

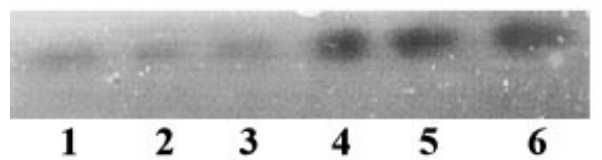

A'

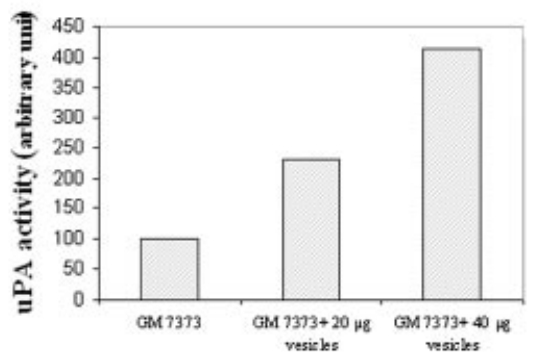

B'
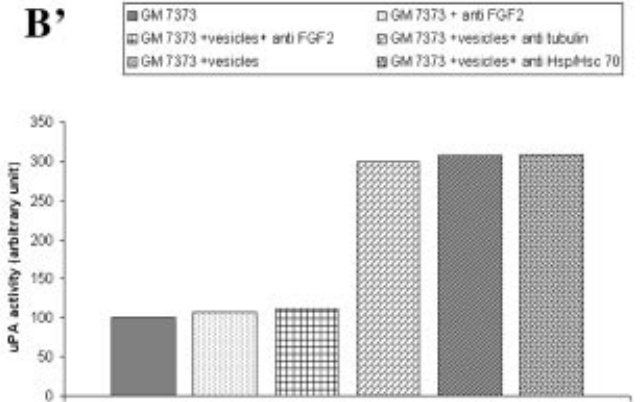

Fig. 7. Induction of uPA activity in GM7373 cells by FGF-2 contained in mesoangioblast vesicles. A: Zymographic assay to measure the uPA activity in GM7373 cells incubated with 0, 20, or $40 \mu$ g of A6 mesoangioblast vesicles (lanes I, 2, 3, respectively). B: Zymographic assay to measure the uPA activity of: Lane I: uPA activity of untreated GM7373 cells; Lane 2: uPA activity of GM7373 cells growing in the presence of $2.5 \mu \mathrm{g}$ of inhibitory anti-FGF2 monoclonal antibodies; Lane 3: uPA activity of GM7373 cells growing in the presence of mesoangioblast vesicles $+2.5 \mu \mathrm{g}$ of inhibitory anti-FGF2 monoclonal antibodies; Lane 4: uPA activity of GM7373 cells growing in the presence of mesoangioblast vesicles $+2.5 \mu \mathrm{g}$ of anti-tubulin- $\beta$ antibodies; Lane 5: uPA activity of GM7373 cells growing in the presence of mesoangioblast vesicles; Lane 6: uPA activity of GM7373 cells growing in the presence of mesoangioblast vesicles $+2.5 \mu \mathrm{g}$ of anti-Hsp/Hsc70 antibodies. $\left(\mathrm{A}^{\prime}, \mathrm{B}^{\prime}\right)$ These data represents densitometric value of uPA activity expressed in arbitrary units, considering 100 the basal uPA activity.

deposition of collagen that occurs in dystrophic muscles of aged mice, and thereby improves the effectiveness of subsequent mesoangioblast transplantation therapy (Gargioli et al., 2008). Moreover, they found that MMP-9 secreted by polarized macrophages, together with HMGB-I and TNF- $\alpha$, affects mesoangioblast migration (Lolmede et al., 2009). Thus, the finding that mesoangioblasts themselves produce and release active MMP-9 and MMP-2 through vesicle production could explain the beneficial effects, observed in mice after delivery of mesoangioblasts in experimental models of tissue repair (Sampaolesi et al., 2003, 2006; Galli et al., 2005; Galvez et al., 2006). The secretion of MMP-2 and MMP-9 in their active form by mesoangioblasts could also facilitate the HMGB-Idependent migration of these cells to sites of inflammation. We propose that mesoangioblasts, experimentally delivered to the vicinity of damaged tissues, could release active MMP-9 and thereby support the activity of macrophages.

In A6 cultured cells, vesicle shedding was also evident at low-oxygen tension, similar to that characteristic of mouse tissues. This is important because after experimental injection into the circulation, these cells reach areas of inflammation where the oxygen tension is lower than that at which they are usually grown in culture. Thus, although the vesicle production we demonstrated was observed in vitro, it is reasonable to suppose that mesoangioblasts also release vesicles in vivo. The data presented here, however, do not preclude the possibility that other tissue microenvironmental factors may modulate or disrupt this process.

We conclude that the production of vesicles by mesoangioblasts may be a mechanism for releasing signaling molecules in a protected form. Although an analysis of the protein profile of vesicles revealed a complex protein pattern, we have clearly demonstrated that two types of proteinsFGF-2 and MMPs - that are known to be important in tissue repair are present in an active form. These findings suggest that mesoangioblasts themselves, through the secretion of specific paracrine signals and factors in membrane vesicles, make damaged tissues more amenable to mesoangioblast cell therapy.

\section{Acknowledgments}

We thank Giulio Cossu (Department of Biology, University of Milan and Division of Regenerative Medicine San Raffaele, Milan, Italy) for providing A6 mesoangioblasts and for helpful suggestions. We also thank M. Letizia Vittorelli (University of Palermo, Italy) for the gift of GM7373 cells and HTI080 cells and Monica Salamone (University of Palermo, Italy) for advice on collegen gels.

\section{Literature Cited}

Barnouin K. 2004. Two-dimensional gel electrophoresis for analysis of protein complexes Methods Mol Biol 261:479-498.

Beaudoin AR, Grondin G. 1991. Shedding of vesicular material from the cell surface of eukaryotic cells: Different cellular phenomena. Biochim Biophys Acta 1071:203-219.

Chavez-Muñoz C, Kilani RT, Ghahary A. 2009. Profile of exosomes related proteins released by differentiated and undifferentiated human keratinocytes. J Cell Physiol 221:221-231. Cocucci E, Racchetti G, Meldolesi J. 2009. Shedding microvesicles: Artefacts no more. Trends Cell Biol 19:43-51

D’Agostino S, Salamone M, Di Liegro I, Vittorelli ML. 2006. Membrane vesicles shed by oligodendroglioma cells induce neuronal apoptosis. Int J Oncol 29:1075-1085.

De Angelis L, Berghella L, Coletta M, Lattanzi L, Zanchi M, Cusella-De Angelis MG, Ponzetto C, Cossu G. 1999. Skeletal myogenic progenitors originating from embryonic dorsal aorta coexpress endothelial and myogenic markers and contribute to postnatal muscle growth and regeneration. J Cell Biol 147:869-878.

Del Conde I, Shrimpton CN, Thiagarajan P, López JA. 2005. Tissue-factor-bearing microvesicles arise from lipid rafts and fuse with activated platelets to initiate coagulation. Blood 106:1604-1611. 
Dolo V, Ginestra A, Ghersi G, Nagase H, Vittorelli ML. 1994. Human breast carcinoma cells cultured in the presence of serum shed membrane vesicles rich in gelatinolytic activities. Submicrosc Cytol Pathol 26:173-180.

Donati C, Cencetti F, De Palma C, Rapizzi E, Brunelli S, Cossu G, Clementi E, Bruni P. 2009. TGFbeta protects mesoangioblasts from apoptosis via sphingosine kinase-I regulation. Cell Signal 21:228-236.

Freyssinet JM. 2003. Cellular microparticles: What are they bad or good for? J Thromb Haemost 1:1655-1662.

Galli M, Bevers EM, Comfurius P, Barbui T, Zwaal RF. 1993. Effect of antiphospholipid antibodies on procoagulant activity of activated platelets and platelet-derived microvesicles. Br J Haematol 83:466-472.

Galli D, Innocenzi A, Staszewsky L, Zanetta L, Sampaolesi M, Bai A, Martinoli E, Carlo E, Balconi G, Fiordaliso F, Cimenti S, Cusella G, Decana E, Cossu G, Latini R. 2005. Mesoangioblasts, vessel-associated multipotent stem cells, repair the infarcted heart by multiple cellular mechanisms: A comparison with bone marrow progenitors, fibroblasts, and endothelial cells. Arterioscler Thromb Vasc Biol 25:692-697.

Galvez BG, Sampaolesi M, Brunelli S, Covarello D, Gavina M, Rossi B, Constantin G, Torrente Y, Cossu G. 2006. Complete repair of dystrophic skeletal muscle by mesoangioblasts with enhanced migration ability. J Cell Biol 174:231-243.

Gargioli C, Coletta M, De Grandis F, Cannata SM, Cossu G. 2008. PIGF-MMP-9-expressing cells restore microcirculation and efficacy of cell therapy in aged dystrophic muscle. $\mathrm{Nat}$ Med 14:973-978

Geraci F, Turturici G, Galli D, Cossu G, Giudice G, Sconzo G. 2006. Stress response in mesoangioblast stem cells. Cell Death Differ 13:1057-1063.

Ginestra A, Monea S, Seghezzi G, Dolo V, Nagase H, Mignatti P, Vittorelli ML. 1997. Urokinase plasminogen activator and gelatinases are associated with membrane vesicles shed by human HTI080 fibrosarcoma cells. J Biol Chem 272:17216-17222

Hägerstrand H, Mrówczyńska L, Salzer U, Prohaska R, Michelsen KA, Kralj-Iglic V, Iglic A. 2006. Curvature-dependent lateral distribution of raft markers in the human erythrocyte membrane. Mol Membr Biol 23:277-288.

Hegmans JP, Bard MP, Hemmes A, Luider TM, Kleijmeer MJ, Prins JB, Zitvogel L, Burgers SA Hoogsteden HC, Lambrecht BN. 2004. Proteomic analysis of exosomes secreted by human mesothelioma cells. Am J Pathol I64:1807-1815.

Hugel B, Martinez MC, Kunzelmann C, Freyssinet J-M. 2005. Membrane microparticles: Two sides of the coin. Physiology 20:22-27.

Lolmede K, Campana L, Vezzosi M, Bosurgi L, Tonlorenzi R, Clementi E, Bianchi ME, Cossu G Manfredi AA, Brunelli S, Rovere-Querini P. 2009. Inflammatory and alternatively activated human macrophages attract vessel-associated stem cells, relying on separate HMGBI- and MMP-9-dependent pathways. J Leukoc Biol 85:779-787.

Martínez MC, Tesse A, Zobairi F, Andriantsitohaina R. 2005. Shed membrane microparticles from circulating and vascular cells in regulating vascular function. Am J Physiol Heart Circ Physiol 288:H1004-HI009.

McCloskey TW, Chavan S, Lakshmi Tamma SM, Pahwa S. 1998. Comparison of seven quantitative assays to assess lymphocyte cell death during HIV infection: Measurement of induced apoptosis in anti-Fas-treated Jurkat cells and spontaneous apoptosis in peripheral blood mononuclear cells from children infected with HIV. AIDS Res Hum Retroviruses 14:1413-1422.

Millimaggi D, Festuccia C, Angelucci A, D'Ascenzo S, Rucci N, Flati S, Bologna M, Teti A, Pavan A, Dolo V. 2006. Osteoblast-conditioned media stimulate membrane vesicle shedding in prostate cancer cells. Int J Oncol 28:909-914.
Minasi MG, Riminucci M, De Angelis L, Borello U, Berarducci B, Innocenzi A, Caprioli A Strabella D, Baiocchi M, De Maria R, Boratto R, Jaffredo T, Broccoli V, Bianco P, Cossu G. 2002. The meso-angioblast: a multipotent, self-renewing cell that originates from the dorsal aorta and differentiates into most mesodermal tissues. Development 129:27732783

Noble PB. 1987. Extracellular matrix and cell migration: Locomotory characteristics of MOS II cells within a three-dimensional hydrated collagen lattice. J Cell Sci 87:24I-248.

Palumbo R, Sampaolesi M, De Marchis F, Tonlorenzi R, Colombetti S, Mondino A, Cossu G, Bianchi ME. 2004. Extracellular HMGBI, a signal of tissue damage, induces mesoangioblast migration and proliferation. J Cell Biol I64:44|-449.

Pilzer D, Gasser O, Moskovich O, Schifferli JA, Fishelson Z. 2005. Emission of membrane vesicles: Roles in complement resistance, immunity and cancer. Springer Semin Immunopathol 27:75-87.

Ratajczak J, Wysoczynski M, Hayek F, Janowska-Wieczorek A, Ratajczak MZ. 2006a. Membrane-derived microvesicles: Important and underappreciated mediators of cell-tocell communication. Leukemia 20:|487-|495.

Ratajczak J, Miekus K, Kucia M, Zhang J, Reca R, Dvorak P, Ratajczak MZ. 2006b. Embryonic stem cell-derived microvesicles reprogram hematopoietic progenitors: Evidence for horizontal transfer of mRNA and protein delivery. Leukemia 20:847-856.

Sampaolesi M, Torrente Y, Innocenzi A, Tonlorenzi R, D’Antona G, Pellegrino MA, Barresi R, Bresolin N, De Angelis MG, Campbell KP, Bottinelli R, Cossu G. 2003. Cell therapy of alpha-sarcoglycan null dystrophic mice through intra-arterial delivery of mesoangioblasts. Science 301:487-492.

Sampaolesi M, Blot S, D'Antona G, Granger N, Tonlorenzi R, Innocenzi A, Mogol P, Thibaud JL, Galvez BG, Barthélémy I, Perani L, Mantero S, Guttinger M, Pansarasa O, Rinaldi C. Cusella De Angelis MG, Torrente Y, Bordignon C, Bottinelli R, Cossu G. 2006 Mesoangioblast stem cells ameliorate muscle function in dystrophic dogs. Nature 444:574 579

Stein JM, Luzio JP. 1991. Ectocytosis caused by sublytic autologous complement attack on human neutrophils. The sorting of endogenous plasma-membrane proteins and lipids into shed vesicles. Biochem J 274:8I-86.

Taraboletti G, D'Ascenzo S, Borsotti P, Giavazzi R, Pavan A, Dolo V. 2002. Shedding of the matrix metalloproteinases MMP-2, MMP9, and MTI-MMP as membrane vesicle-associated components by endothelial cells. Am J Pathol 160:673-680.

Taraboletti G, D'Ascenzo S, Giusti I, Marchetti D, Borsotti P, Millimaggi D, Giavazzi R, Pavan A, Dolo V. 2006. Bioavailability of VEGF in tumor-shed vesicles depends on vesicle burst induced by acidic $\mathrm{pH}$. Neoplasia 8:96-103.

Taverna S, Ghersi G, Ginestra A, Rigoglioso S, Pecorella S, Alaimo G, Saladino F, Dolo V Dell'Era P, Pavan A, Pizzolanti G, Mignatti P, Presta M, Vittorelli ML. 2003. Shedding of membrane vesicles mediates fibroblast growth factor-2 release from cells. J Biol Chem 278:51911-51919.

Taverna S, Rigoglioso S, Salamone M, Vittorelli ML. 2008. Intracellular trafficking of endogenous fibroblast growth factor-2. FEBS J 275:1579-1592.

Vassalli JD, Dayer JM, Wohlwend A, Belin D. 1984. Concomitant secretion of prourokinase and of a plasminogen activator-specific inhibitor by cultured human monocytesmacrophages. J Exp Med 159:1653-1668.

Wang XQ, Paller AS. 2006. Lipid rafts: Membrane triage centers. J Invest Dermatol I26:95I-953. Wright WE, Shay JW. 2006. Inexpensive low-oxygen incubators. Nat Protocol I:2088-2090. Yuan A, Farber EL, Rapoport AL, Tejada D, Deniskin R, Akhmedov NB, Farber DB. 2009. Transfer of microRNAs by embryonic stem cell microvesicles. PLoS ONE 4:e4722. 